\title{
Emerging Methods for Diagnostics and Mitigation of Crop Environmental Stress in a Changing Climate
}

\author{
Soo-Hyung Kim ${ }^{1}$ \\ Center for Urban Horticulture, School of Environmental and Forest Sciences, College of the \\ Environment, University of Washington, Box 354115, Seattle, WA 98195-4115 \\ Bert Cregg \\ Department of Horticulture, Department of Forestry, Michigan State University, A214 Plant and \\ Soil Sciences Building, East Lansing, MI 48824
}

Additional index words. climate change, environmental stress physiology, colloquium, global warming, horticulture, specialty crops

\begin{abstract}
Innovative approaches are required for improving crop productivity and quality to meet the increasing demand for providing food, energy, and other services for growing populations in a changing climate. The colloquium sponsored by the Environmental Stress Physiology (STRS) Working Group at the 2011 American Society for Horticultural Science (ASHS) annual conference served as a forum to bring together several of the emerging methods for diagnosing, monitoring, and mitigating crop environmental stress with an emphasis on horticultural, physiological, and ecological approaches. These methods are likely to be readily applicable for many research areas in specialty crops in the context of climate change. The colloquium articles in this volume provide a foundation and context to lead dialogues and initiate research themes for developing adaptive strategies to minimize climate impacts on horticultural crop production in a changing climate.
\end{abstract}

Crops face numerous abiotic and biotic stresses throughout their lifetimes. These environmental pressures are intensifying in the form of extreme weather events, drought, salinity, invasive insects and pathogens, and other stressors in a changing climate. The need for improving crop productivity and quality with enhanced resource use efficiencies (e.g., water, nitrogen) has increased immensely to meet the demand for providing food, energy, and other goods and services for a rapidly increasing global population.

A growing volume of recent scientific research is devoted to assessing climate change impacts and developing adaptation strategies in agriculture for achieving food security in future climates. Many of these studies have focused on staple food and other major crops such as rice, maize, wheat, soybean, and cotton. By contrast, relatively little attention has been paid to specialty crops in light of climate change (Fig. 1A). A thorough assessment of climate change impacts on specialty crops, coupled with targeted development of adaptation strategies, is urgently needed. Research on environmental stress physiology can provide fundamental knowledge and forms the basis for tools to develop climate adaptation strategies in horticulture.

Received for publication 2 Apr. 2012. Accepted for publication 12 Apr. 2012.

This paper was part of the colloquium, "Emerging Techniques to Evaluate and Mitigate Crop Environmental Stress in a Changing Climate" held 28 Sept. 2011 at the ASHS Conference, Waikoloa, HI, and sponsored by the Environmental Stress Physiology (STRS) Working Group.

This colloquium was sponsored by the Environmental Stress Physiology Working Group of the American Society for Horticultural Science, and supported in part by Acadian Plant Science, NovaSource/TKI, Precision Laboratories, LI-COR BioSciences, and Valent Bioscience.

${ }^{1}$ To whom reprint requests should be addressed; e-mailsoohkim@u.washington.edu.
An impressive legacy of environmental stress research in horticultural crops has spawned numerous fundamental discoveries and a wealth of knowledge that can be directly or indirectly applied to climate change research. For example, over 150 studies have been published on crop heat stress in specialty crops in horticultural journals according to our literature search in the Web of Science database (Thompson Reuters, New York, NY) as of Dec. 2011 (Fig. 1B). Many of these articles did not specify "climate change" or "global warming" in their keywords list (Fig. 1A). However, their findings on crop heat stress have direct implications for climate change research and are likely to provide critical insights for successful climate adaptations in agriculture. Another example of the relevancy of horticultural research to climate change science comes from a plethora of carbon dioxide $\left(\mathrm{CO}_{2}\right)$ enrichment studies in the controlled environment whose findings have built the foundations of further elevated $\mathrm{CO}_{2}$ studies (e.g., Jiao and Grodzinski, 1998; Kimball, 1983; Mortensen, 1987; Mortensen and Moe, 1983; Prior et al., 2011).

Horticultural scientists are working to improve crop stress tolerance through breeding (both conventional and molecular), genetic engineering, and other means involving changes in crop genetics (e.g., Bassett et al., 2011; Wisniewski et al., 2011). These approaches are valuable methods, especially as long-term adaptive solutions to climate change. Equally valuable approaches, particularly for short-term climate adaptations, are likely to include selecting appropriate cultivars or species, adopting cultural practices for reducing crop environmental stress, and exploring novel tools and approaches for mitigating plant stress in a changing climate.

In conjunction with crop improvement efforts, many critical advances have been made in developing methods to diagnose, monitor, and mitigate crop environmental stresses. These physiological and ecological methods complement genetic approaches for improving stress tolerances in crops. The colloquium sponsored by the ASHS STRS Working Group served as a forum to bring together several of these emerging, novel methods for diagnosing, monitoring, and mitigating crop environmental stress. An emphasis was placed on horticultural, physiological, and ecological approaches that bear direct implications in climate change research. The specific aims of this colloquium were to introduce: 1) novel and emerging methods for early detection and assessment of plant stress; 2) novel and emerging methods for mitigating plant stress; and 3) applications of these methods in horticulture.

Accordingly, the colloquium consisted of two main themes: 1) stress diagnostics; and 2) stress mitigation. The stress diagnostics addressed in the colloquium represent recent advances in detecting and diagnosing crop stresses at leaf, whole-plant, or canopy scales. In the stress mitigation section, authors presented new and emerging techniques for mitigating the physiological impacts of environmental stresses and their application to horticultural crops.

\section{STRESS DIAGNOSTICS}

Bunce (2012) illustrates a set of novel gas-exchange methods that can be used to estimate the mesophyll conductance $\left(g_{\mathrm{m}}\right)$ and non-stomatal inhibition of photosynthesis in response to water deficits. Recently, there has been renewed interest in the roles of $g_{\mathrm{m}}$ in limiting $\mathrm{C}_{3}$ photosynthesis (Flexas et al., 2008). However, an accurate experimental determination of $g_{\mathrm{m}}$ remains challenging (Pons et al., 2009). All existing methods involve various degrees of uncertainties based on their specific assumptions associated with models being used (Pons et al., 2009). The new methods described by Bunce (2012) use the oxygen $\left(\mathrm{O}_{2}\right)$ sensitivity of $\mathrm{C}_{3}$ photosynthesis 


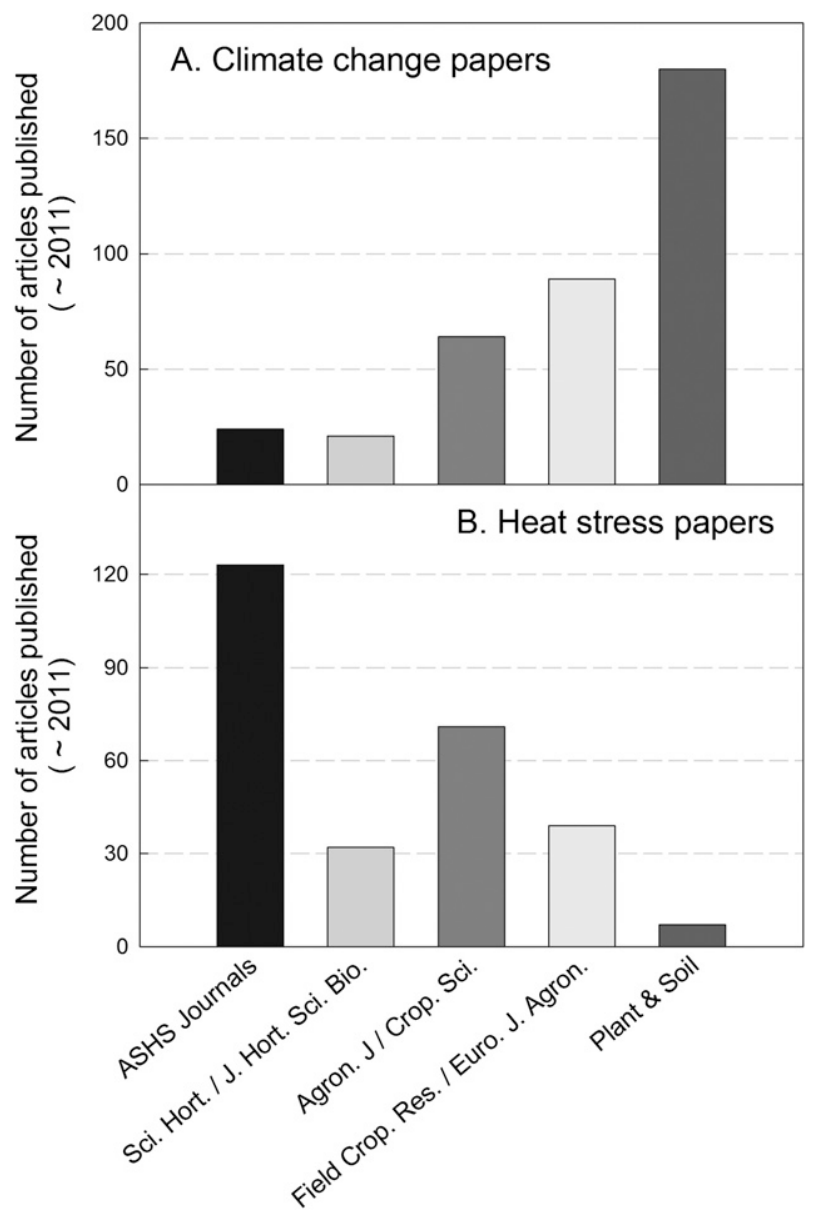

Fig. 1. Number of articles listing "climate change, global change, or global warming" (A) and "heat stress" (B) as keyword(s) that have been published in selected scientific journals covering crop sciences up to 2011 in the Web of Science database (Thomson Reuters, New York, NY). Relatively fewer "climate change" articles have been published in horticultural journals (A). However, numerous articles on key topics (e.g., heat stress) that bear significant implications for climate change research have been published in these journals historically (B). Full journal titles included in the search are: HortScience, The Journal of American Society for Horticultural Science, HortTechnology (ASHS Journals); Scientia Horticulturae (Sci. Hort.); Journal of Horticultural Science and Biotechnology (J. Hort. Sci. Bio.); Agronomy Journal (Agron. J); Crop Science (Crop. Sci.); Field Crops Research (Field Crop. Res.); European Journal of Agronomy; and Plant and Soil.

and a biochemical model of $\mathrm{C}_{3}$ photosynthesis (Farquhar et al., 1980) to estimate the conductance of $\mathrm{CO}_{2}$ from the intercellular air spaces to the site of carboxylation inside the chloroplast. This method has been found to compare well with other methods (Bunce, 2009) and is a welcome new addition to the existing methods, especially for those researchers and educators who lack the abilities to measure chlorophyll fluorescence and gas exchange simultaneously or to measure realtime carbon isotope ratios using an inline mass spectrometry. In addition, Bunce (2012) introduces a unique method to temporarily reverse stomatal closure under water deficits in different species by exposing a leaf to low $\mathrm{CO}_{2}$. This technique allows for assessing the non-stomatal limitations of photosynthesis in response to water stress. These two techniques are novel and easy to use for physiologists and breeders to evaluate and quantify different limitations in photosynthesis of $\mathrm{C}_{3}$ plants in a changing climate.

Merchant (2012) provides new insights on stress responses by integrating a variety of techniques to analyze phloem sap, including stable carbon isotope ratios (i.e., $\delta^{13} \mathrm{C}$ ) from different phloem sources, phloem osmotic potential $\left(\psi_{\mathrm{S}}\right)$, and phloem metabolite concentrations. For example, $\delta^{13} \mathrm{C}$ of phloem sap collected from bleeding at the distal tip of the fruit correlated best with modeled predictions of $\delta^{13} \mathrm{C}$ from gas exchange (Farquhar et al., 1980) in Lupinus angustifolius, suggesting the use of this method for evaluating the short-term plant performance as a surrogate of whole-plant gas exchange (Merchant, 2012). A consistent enrichment of $\approx 4 \%$ in $\delta^{13} \mathrm{C}$ of phloem sap from fruit bleeding against the modeled value has been observed but the reasons for this discrepancy remains to be understood (Merchant, 2012). Concentrations of phloem sugars and sugar alcohols are well correlated with $\delta^{13} \mathrm{C}$ of phloem sap and, along with phloem $\psi_{\mathrm{S}}$, are thought to be useful surrogates of $\delta^{13} \mathrm{C}$. Considerable variability has been observed when the phloem $\psi_{\mathrm{S}}$ was correlated against phloem $\delta^{13} \mathrm{C}$, suggesting involvement of other metabolites affecting the relationship (Merchant, 2012).
These results have ramifications for research and field applications of sap diagnostics such as the use of refractometry.

Glenn (2012a) reviews recent advances and applications of infrared and chlorophyll fluorescence imaging techniques (e.g., thermal frequency distribution analysis, differential thermal analysis, time lapse photography of green fluorescent protein-induced fluorescence, real-time imaging of reactive oxygen species) for evaluation of whole-plant as well as fruit physiological stresses. The ability to capture spatial and temporal variability makes these technologies particularly useful for plant stress evaluations in laboratory and/ or field conditions. Glenn (2012a) discusses the current state, strengths, and limitations of these technologies in the context of horticultural stress physiology.

\section{STRESS MITIGATION}

Rusty Rodriguez presented evidence from a series of experiments of plant stress mitigation by Class 2 fungal endophytes (Woodward et al., 2012). Class 2 endophytes are defined as fungal endophytes that colonize both aboveand belowground tissues of host plants with broad host ranges, whereas their diversity within individual host plants is limited (Rodriguez et al., 2009). Class 2 endophytes isolated from various habitats have been found to promote growth and ameliorate abiotic stresses resulting from salinity, drought, heat, and cold temperatures (Redman et al., 2011; Rodriguez et al., 2009). Woodward et al. (2012) proposes the use of fungal endophytes as an epigenetic approach to mitigating environmental stresses on crops resulting from climate change. Although the physiological mechanisms of how these endophytes confer stress tolerances in a diverse crop are still being discovered (Redman et al., 2011; Rodriguez and Redman, 2005), the use of symbionts such as Class 2 fungal endophytes might serve as an intermediate synergistic step that complements crop improvement efforts for adapting to climate change.

Jithesh et al. (2012) discuss recent research in Balakrishnan Prithiviraj's laboratory, which integrates the application of functional genomics to understanding biochemical and physiological responses to salinity stress. This novel work traces its origins to observations of upregulation of sodium chloride $(\mathrm{NaCl})$ tolerance genes in response to application of extracts of brown microalgae, Ascophyllum nodosum (ANE). In addition, application of ANE resulted in down regulation of many genes during salinity stress. Jithesh et al. (2012) reported the screening of 18 T-DNA knockout mutations of the downregulated genes including a pectin methyl esterase inhibitor gene mutant (pmei1-1). In particular, pmei1-1 showed a clear increase in salt tolerance at 75 and 100 $\mathrm{mm} \mathrm{NaCl}$ based on root growth mass. The authors suggest that $\mathrm{NaCl}$ tolerance in pmeil-1 plants may be related to differential expression of coexpressed genes. This study provides 
a glimpse of the potential and promise of molecular approaches in understanding and ultimately improving crop stress tolerance in conjunction with horticultural techniques such as application of ANE.

Glenn (2012b) examines the potential of using kaolin-based particle films for plant stress mitigation in the context of climate change by providing a review of experimental studies that investigated the effects of kaolin particle films on reducing heat stress, solar injury, and insect damage. Improved carbon gain and water use efficiency at the whole-canopy level have also been observed with kaolin particle films. Several studies have attributed this physiological benefit and related growth promotion to an enhancement in diffuse light distribution inside the canopy as a result of the reflective nature of kaolin particle films (Glenn, 2009, 2012b; Rosati et al., 2007). Glenn (2009, 2012 b) elucidates potential physiological mechanisms for heat stress and sunburn mitigation. Based on a 10-year study, Glenn (Glenn, 2012b) illustrates that fruit yield gain by kaolin particle films is more pronounced as the growing season temperature increases in apple.

\section{CONCLUDING REMARKS}

The research methods highlighted in the colloquium represent novel approaches that are likely to be readily applicable for stress physiology research in horticultural crops in the context of climate change. The colloquium articles provide a foundation and context to lead dialogues and initiate research themes for developing adaptive strategies to minimize climate impacts on horticultural crop production in a changing climate. Many other approaches not covered in the colloquium also exist that can be effective tools for diagnosing and mitigating plant stress in horticultural crops. We look forward to future endeavors arising from the horticultural science community that expand the scope of this colloquium.

\section{Literature Cited}

Bassett, C.L., D.M. Glenn, P.L. Forsline, M.E. Wisniewski, and R.E. Farrell. 2011. Characterizing water use efficiency and water deficit responses in apple (Malus $\times$ domestica Borkh. and Malus sieversii Ledeb.). M. Roem. HortScience 46:1079-1084.

Bunce, J. 2012. Using new gas exchange methods to estimate mesophyll conductance and nonstomatal inhibition of photosynthesis caused by water deficits. HortScience 47:687-690.

Bunce, J.A. 2009. Use of the response of photosynthesis to oxygen to estimate mesophyll conductance to carbon dioxide in waterstressed soybean leaves. Plant Cell Environ. 32:875-881.

Farquhar, G.D., S. von Caemmerer, and J.A. Berry. 1980. A biochemical model of photosynthetic $\mathrm{CO}_{2}$ assimilation in leaves of $\mathrm{C}_{3}$ species. Planta (Berlin) 149:78-90.

Flexas, J., M. Ribas-Carbo, A. Diaz-Espej, J. Galmes, and H. Medrano. 2008. Mesophyll conductance to $\mathrm{CO}_{2}$ : Current knowledge and future prospects. Plant Cell Environ. 31:602621.

Glenn, D.M. 2009. Particle film mechanisms of action that reduce the effect of environmental stress in 'Empire' apple. J. Amer. Soc. Hort. Sci. 134:314-321.

Glenn, D.M. 2012a. Infrared and chlorophyll fluorescence imaging methods for stress evaluation. HortScience 47:697-698.

Glenn, D.M. 2012b. The mechanisms of plant stress mitigation by kaolin-based particle films and applications in horticultural and agricultural crops. HortScience 47:710-711.

Jiao, J. and B. Grodzinski. 1998. Environmental influences on photosynthesis and carbon export in greenhouse roses during development of the flowering shoot. J. Amer. Soc. Hort. Sci. 123:1081-1088.

Jithesh, M.N., O.S.D. Wally, I. Manfield, A.T. Critchley, D. Hiltz, and B. Prithiviraj. 2012. Analysis of seaweed extract induced transcriptome leads to identification of a negative regulator of salt tolerance in Arabidopsis. HortScience 47:704-709.

Kimball, B.A. 1983. Carbon dioxide and agricultural yield: An assemblage and analysis of 430 prior observations. Agron. J. 75:779-788.

Merchant, A. 2012. Developing phloem $\delta^{13} \mathrm{C}$ and sugar composition as indicators of water deficit in Lupinus angustifolius. HortScience 47:691696.

Mortensen, L.M. 1987. Review: $\mathrm{CO}_{2}$ enrichment in greenhouses. Crop responses. Sci. Hort. 33: $1-25$.

Mortensen, L.M. and R. Moe. 1983. Growth responses of some greenhouse plants to environment. V. Effect of $\mathrm{CO}_{2}, \mathrm{O}_{2}$ and light on net photosynthetic rate in Chrysanthemum morifolium Ramat. Sci. Hort. 19:133-140.

Pons, T.L., J. Flexas, S. von Caemmerer, J.R. Evans, B. Genty, M. Ribas-Carbo, and E. Brugnoli. 2009. Estimating mesophyll conductance to $\mathrm{CO}_{2}$ : Methodology, potential errors, and recommendations. J. Expt. Bot. 60:2217-2234.

Prior, S.A., G.B. Runion, S.C. Marble, H.H. Rogers, C.H. Gilliam, and H.A. Torbert. 2011. A review of elevated atmospheric $\mathrm{CO}_{2}$ effects on plant growth and water relations: Implications for horticulture. HortScience 46:158-162.

Redman, R.S., Y.O. Kim, C.J.D.A. Woodward, C. Greer, L. Espino, S.L. Doty, and R.J. Rodriguez. 2011. Increased fitness of rice plants to abiotic stress via habitat adapted symbiosis: A strategy for mitigating impacts of climate change. PLoS One 6:e14823.

Rodriguez, R. and R. Redman. 2005. Balancing the generation and elimination of reactive oxygen species. Proc. Natl. Acad. Sci. USA 102:31753176.

Rodriguez, R.J., J.F. White, A.E. Arnold, and R.S. Redman. 2009. Fungal endophytes: Diversity and functional roles. New Phytol. 182:314-330

Rosati, A., S.G. Metcalf, R.P. Buchner, A.E. Fulton, and B.D. Lampinen. 2007. Effects of kaolin application on light absorption and distribution, radiation use efficiency and photosynthesis of almond and walnut canopies. Ann. Bot. (Lond.) 99:255-263.

Wisniewski, M., J. Norelli, C. Bassett, T. Artlip, and D. Macarisin. 2011. Ectopic expression of a novel peach (Prunus persica) CBF transcription factor in apple (Malus $\times$ domestica) results in short-day induced dormancy and increased cold hardiness. Planta 233:971983.

Woodward, C., L. Hansen, F. Beckwith, R.S. Redman, and R.J. Rodriguez. 2012. Symbiogenics: An epigenetic approach to mitigating impacts of climate change on plants. HortScience 47:699-703. 